\title{
Assessment of age, education income levels and type of policies of the cardio vascular patients in opting health insurance from tier I and tier II city hospitals of India
}

\author{
Shaima A. Miraj
}

College of Health Management Saudi Electronic University Riyadh Kingdom of Saudi Arabia

\begin{abstract}
In the present study the role of private health care system with regard to health insurance through third party assurance has been evaluated, focus has been made on certain factors such as age, sex, education, income levels and the type of health policies which cardiac insured patients from tier I (Delhi ) and tier II cities (Indore Bhopal ) opt for managing cardio vascular disease. An important conclusion drawn from the present data show that across Delhi, Indore and Bhopal the average age of patients being admitted for the treatment of cardiac ailments was 53 and above, males being more affected than females, which can significantly affect some of the productive life of the individuals and thereby also affecting the working capacity . Education wise the average percentage of policy holders having graduation and above across all the 4 hospitals was 75\%, which clearly suggests that high education levels do have a positive influence. Comparing the income level of the insured cardiac patients the percentage of insured policy holders in all the four private hospitals under study $86 \%$ had a monthly income of more than Rs. 20,000. The data also suggest that the category of people with low income who need health insurance policy the most do not have it. While comparing the corporate versus individual policy holders, it was found that corporate policy holders are significantly more in Tier I cities than Tier II cities as Delhi has an average of almost 32\% corporate insured cardiac patients as against an average of 22\% in collective combine of Indore and Bhopal.
\end{abstract}

KEY WORDS: CARDIAC INSURED PATIENTS, DEMOGRAPHIC, INCOME, EDUCATION LEVELS ACROSS SUPER SPECIALTY HOSPITALS

\section{INTRODUCTION}

Health has assumed as a gigantically growing industry, and the potential is tremendous, as India's spending on health is poorly dismal, being less than $0.7 \%$ of its Gross Domestic Product (GDP), against an average of $0.9 \%$ of the low income countries. As a result, there has been a sudden rise in private hospitals and their suc-

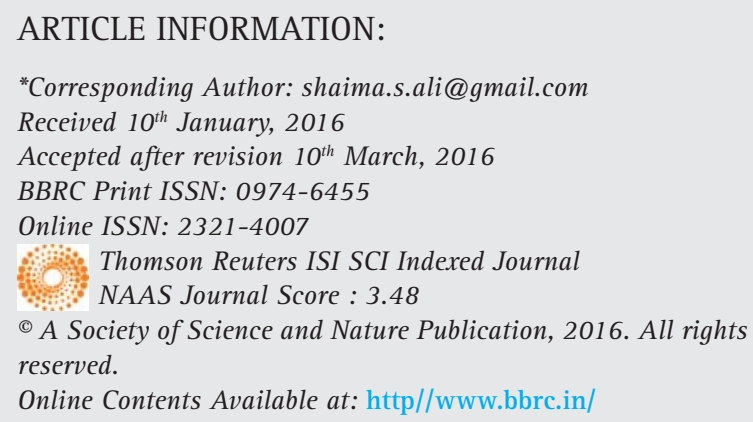


cessful blooming. Hospitals in major cities in India in many cases are run by business houses, using corporate business strategies and high tech specializations, which create demand as well as attract high profile patients as the facilities in some of these hospitals are world class, (Wilson 2009 and HIFA Health Care Information, 2010, Shaima Miraj 2014, 2015a,b).

On the other hand, the marginal presence of the government share in health care leaves the door further wide open for alternative suppliers. The private sector plays a very important role in India's health delivery system and has a wide network of facilities, which cater to health requirements of both the urban and the rural populations. Though the last 5 decades have seen a troubled scenario in India's health care system, however, much progress has been recorded since then. Life expectancy is greater than 63 years, and the India of 2016 is a thriving democracy with a diversified production base, a large scientific community, and an impressive information technology sector. During the same period however, India's record in expanding social opportunities has been uneven. The health and nutritional status of children and women remains poor, and India is routinely ranked among countries performing weakly on overall health performance, (WHO, 2008,Kumar et al., 2012).

With regard to India's health care system, it is still pathetic. India has one of the most fragmented and commercialized health - care systems in the world, where world class care is greatly outweighed by unregulated poor-quality health services. Because public spending on health has remained low, private out-of-pocket expenditures on health are among the highest in the world. The country has withstood the recent global economic crisis and quickly returned to economic growth. Spending on health care in India was an estimated five percent of gross domestic product (GDP) in 2013 and is expected to remain at that level through 2016. Total health care spending in local-currency terms is projected to rise at an annual rate of over 12 percent, from an estimated $\$ 96.3$ billion in 2013 to $\$ 195.7$ billion in 2018. While this rapid growth rate will reflect high inflation, it will also be driven by increasing public and private expenditures on health, (Industry Report, Health Care India, 2014 and Deloitte India Report, 2011 2015).

Health care, far from helping people rise out of poverty, has become an important cause of household impoverishment and debt. The average national health indicators, though showing improvements in recent decades, hide vast regional and social disparities. Although some privileged individuals enjoy excellent health outcomes, others experience the worst imaginable conditions (Balarajan et al., 2012; Paul et al., 2012, Kumar et al. 2012). Health disparities are being exacerbated by unequal economic growth, growing commercialization of health care and poor regulation of costs and quality of care Inequities in the provision of healthcare are one of the greatest challenges we currently face as global citizens-and these demands are only amplified in the developing world, (Health Care Information, 2015 and Shaima Miraj 2014 and 2015).

In the present study the role of private health care system with regard to health insurance through third party assurance has been evaluated, focus has been made on certain factors such as age, education, income levels and the type of health policies which patients from tier I (Delhi ) and tier II cities (Indore Bhopal) have opted for managing cardio vascular ailments in these four state of the art private super specialty hospitals of India.

Two super specialty private hospitals, one of Indore and one of Bhopal, representing MP and two private super specialty hospitals of Delhi were selected on the basis of the bed strength, availability of resources with reference to cardiac care, and most important availability of TPA empanelled with selected hospitals of Indore, Bhopal and Delhi to have a comparative assessment of age, education, income levels and type and duration of policies opted by patients in managing cardiac illness, in different cities. Main objective was to correlate the drivers of age, education, qualifications, income levels, type and durations of policies of cardio vascular patients in opting their health insurance policies from tier I and tier II city hospitals of India

In Madhya Pradesh, Bombay Hospital, Indore and Ayushman Hospital Bhopal regarded the most sophisticated hospitals for treatment of cardiac ailments, attracting patients not only from different parts of the MP but also from adjoining states too, were chosen for the comparative study. In all, about 350 insured cardiac patients were selected for the present study from three cities : Indore, Bhopal and Delhi.100 insured cardiac patients were selected as sample from the private hospital of Indore, out of which, 84 were found usable and have been analyzed in the present study. Similarly in the private hospital of Bhopal, only 50 cardiac insured patients were found in the 8 months of the study. Out of which, 43 were found to be usable and included in the present study.

Delhi being the capital of India and one of the most advanced metropolitan cities in the country today has large number of super specialty cardiac hospitals. Out of which only two were taken for our study. In Fortis hospital, Delhi, about 100 cardiac patients were selected having health insurance and have been evaluated for the present study. Out of which 95 respondents were found usable and have been included in the present study. Likewise, in another super specialty hospital of Delhi, namely Batra Hospital, 100 patients were selected and analysed for studying the role of TPA in managing their 
cardiac ailment, out of 100, 91 respondents were found usable for the present study.

The data were collected from hospital and patient sources using a modified questionnaire for the policyholders adapted from standard Hospital and TPA Information Questionnaire (Suman \&t Mishra, IIFMR \& IHMR, 2007) was used to collect the information .The questionnaire was pilot tested and responded by policyholders. The objective of the questionnaire was to understand the role of age, education and qualifications, income levels and the nature and duration of policy to manage the cardio vascular diseases in four hospitals of Indore Bhopal and Delhi. The data were analysed using STATA and SPSS -17.0.

\section{DATA ANALYSIS AND INTERPRETATION}

This part deals with the analysis of data collected on the basis of questionnaire filled up by the patients admitted for treatment in cardiac departments of private super specialty hospitals based in Indore, Bhopal and Delhi. The questionnaire for patients consisted of the demographic data of the patients with regard to their age, education, income, type and duration of policy. Out of the 100 insured cardiac patients taken for study, 84 responded clearly and found usable for study. The samples were evaluated for sex, age, qualifications income and type and duration of policies of the cardiac patients.

The data analysed in the present investigation with regard to the factors under taken show interesting results. On comparing the educational level of the insured cardiac patients across the 4 hospitals of Indore, Bhopal and Delhi, the following results were seen. Education wise, the total percentage of graduates and above among the insured policy holders in private hospital of Indore was $75 \%$. Comparing on the same criteria in the private hospital of Bhopal, the percentage of graduates and above was found to be $63 \%$ clearly suggesting that higher number of policy holders among cardiac patients were having higher educational qualification.

With reference to the comparison of the educational qualification among the insured policy holders in the private hospitals, $85 \%$ percent of cardiac insured patients were having graduation and above degrees. On similar lines, the educational qualification of patients having graduation and above was 77\%. Thus the average percentage of policy holders having graduation and above across all the 4 hospitals is $75 \%$, which clearly suggests that education levels do have a positive influence. On comparing the income levels of the insured cardiac patients across the 4 hospitals of Indore, Bhopal and Delhi, the percentage of insured policy holders in private hospitals of Indore having monthly income of Rs. 20,000 and above was around 85\%.
Comparing on the same criteria in the private hospital of Bhopal, the percentage of insured policy holders in private hospitals of Indore having monthly income of more than Rs. 20,000 was around $79 \%$.On comparing the percentage of insured policy holders in $1^{\text {st }}$ private hospital of Delhi having monthly income of Rs. 20,000 and more was $88 \%$. On the similar lines, the percentage of insured policy holders in $2^{\text {nd }}$ private hospital of Delhi having monthly income of Rs. 20,000 and above was 91\% . Across all studied cities, the percentage of insured policy holders in all the four private hospitals having monthly income of more than Rs. 20,000 was around $86 \%$, which clearly suggests that income levels are important driving factors to have a positive influence on opting health policy.

The data also suggests that the category of people with low income who need health insurance policy the most do not have it. Secondly around 50\% of insured cardiac patients were found to be in the category of income of Rs. 20,000 - 50,000 suggesting that people earning from this category have the largest share in having health insurance cover .

While comparing the corporate versus individual policy holders in Tier I and II cities it was found that corporate policy holders are more in Tier I cities than Tier II cities. This could be clearly represented from the data which showed that while Delhi has an average of almost 32\% corporate insured cardiac patients as against an average of $22 \%$ in collective combine of Indore and Bhopal. The average difference of $10 \%$ could be due to the fact that there are more industrial corporate houses empanelled with Delhi Hospitals to cater to the health insurance needs of their employees as compared to Indore and Bhopal.

Similarly, on comparing the two categories of policy holders on the number of years since insured, it was found that even though the percentage among corporate policy holders insured less than 3 years was low, but the same could not be reflected when the claim denials ratio was analysed. The average claim denial ratio among corporate policy holders across the 3 cities is 11 $\%$ as compared $27 \%$ in case of Individual policy holders leading to a difference of almost 2.5 times.

The possible reasons for this marked variation may perhaps be due to the care taken by corporate and their human resource department while buying the health policies which are always in bulk as well as custom made for the corporate clients. Secondly the TPAs have been found to be more focussed to provide better services to corporate clients which results in a better overall experience in service level.

In the present study, interesting observation was the fact that the interdependence between health and economic well-being has been well established and there is a huge burden and impact of non communicable diseases like that of cardiovascular diseases which are on 


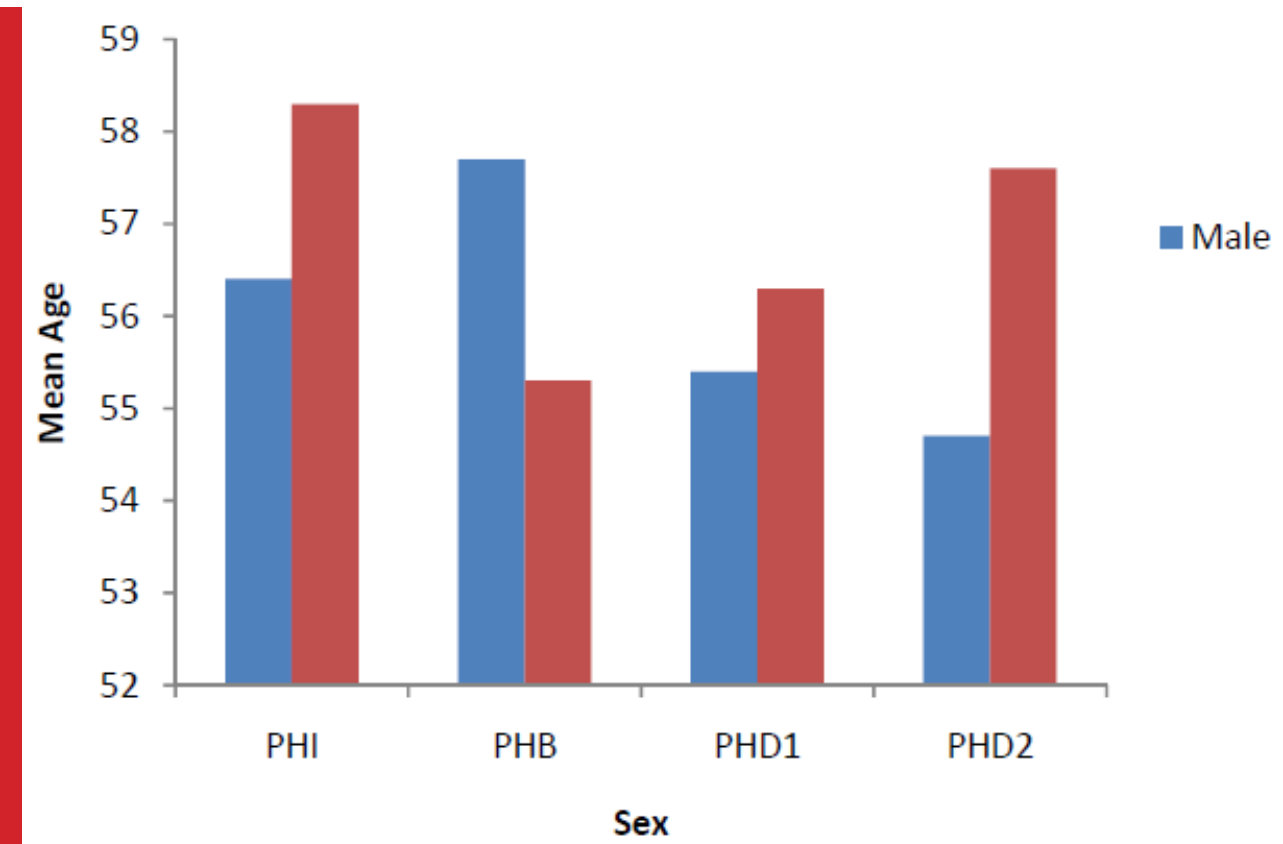

FIGURE 1: Showing the sex and age profiles of the insured cardiac patients from 4 hospitals of MP and Delhi (Private hospital of Indore (PHI), Private hospital of Bhopal( PHB), Private hospital of Delhi (PHD1) and Private hospital of Delhi (PHD 2)

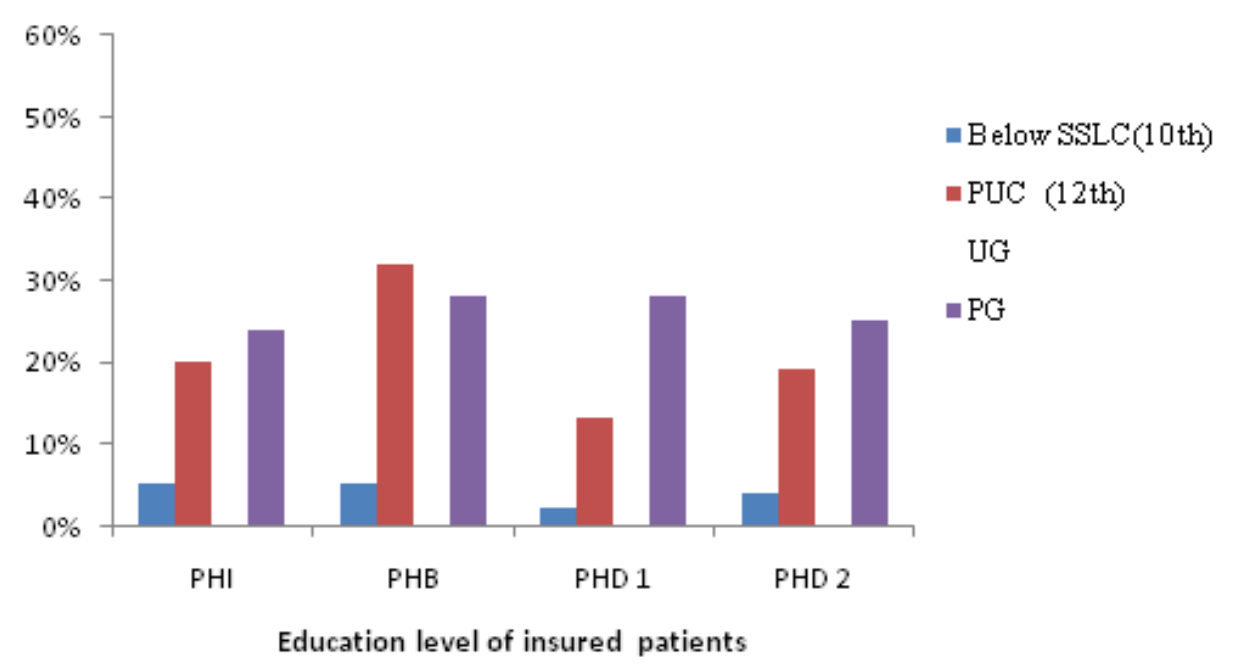

FIGURE 2: Showing the education level of the insured cardiac patients in the selected 4 hospitals of MP and Delhi (Private hospital of Indore (PHI), Private hospital of Bhopal( PHB), Private hospital of Delhi (PHD1), Private hospital of Delhi (PHD 2)

a significant rise, marring the man - hour significantly. Thus the selection of cardiac disease as the chronic illness was justified in the present analysis, as it was found that in all the selected hospitals of three cities, health insurance for this major disease was one of the top most priorities of all the respondents. They are being related to economic growth and development as the data of the present study indicate with reference to large number of cardiac patients being registered in the four selected hospitals from different categories of Bhopal and Indore in Madhya Pradesh and the capital of India Delhi.

An important conclusion drawn from the present findings is that of the age and sex of the cardiac patients, data show that across all the 3 cities of Delhi, Indore 


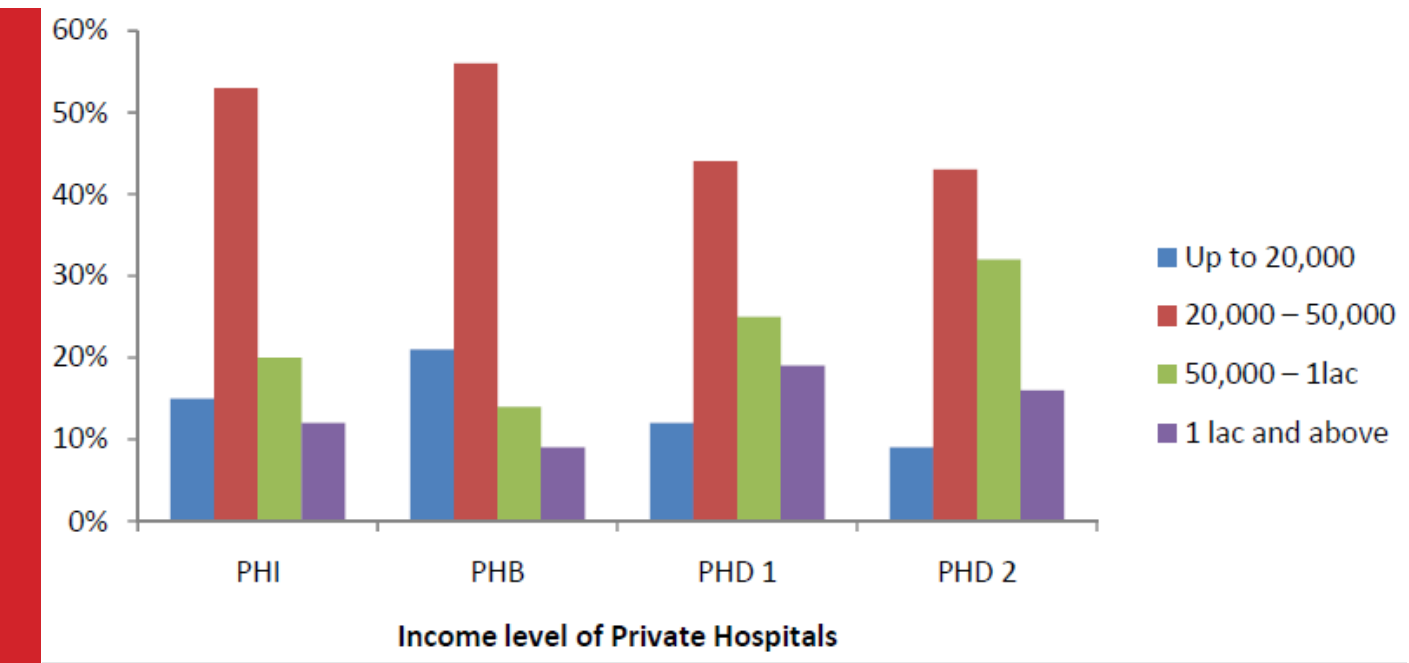

FIGURE 3: Showing the income levels of the insured cardiac patients of 4 hospitals of MP and Delhi

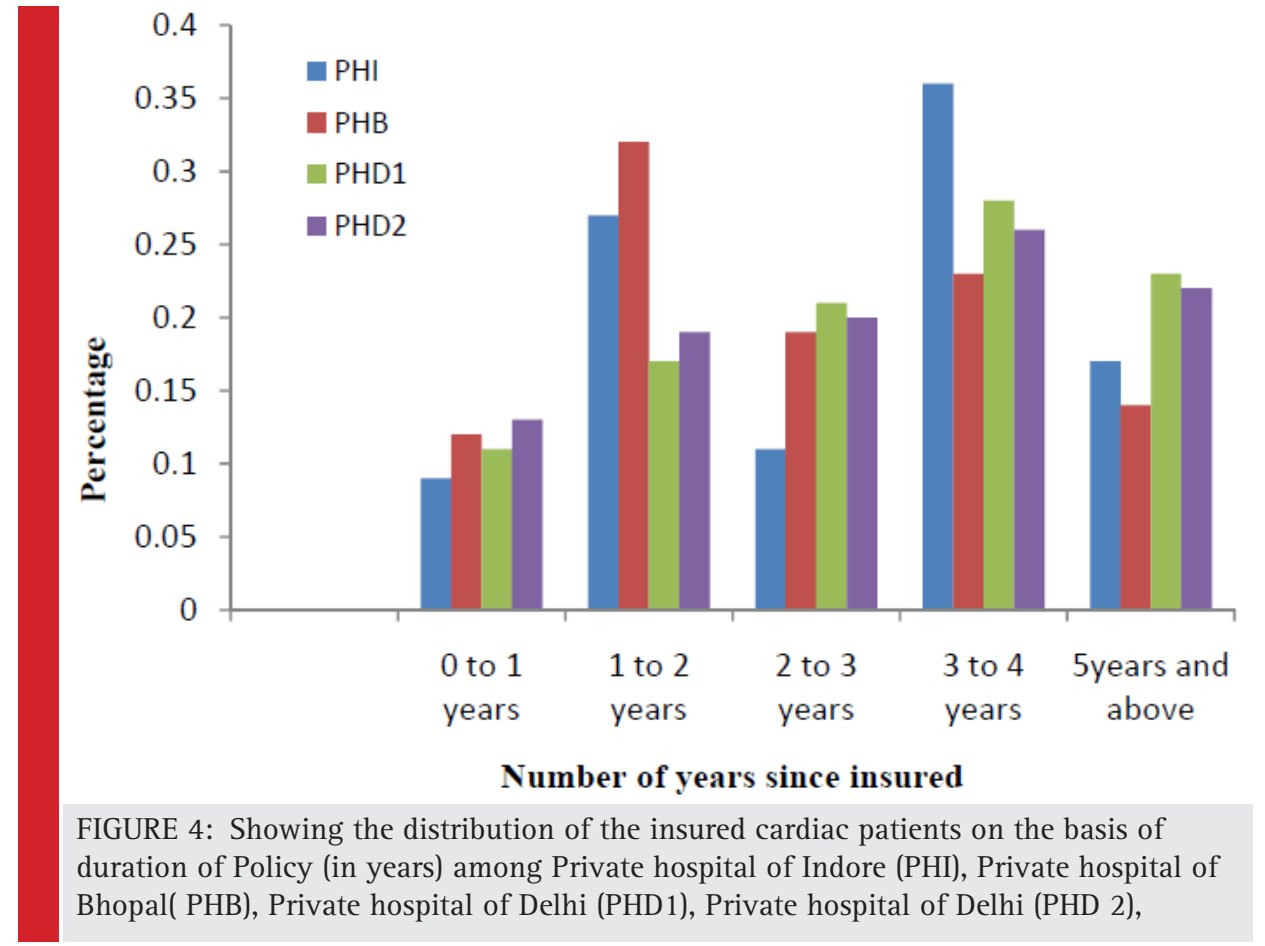

and Bhopal the average age of patients being admitted for the treatment of cardiac ailments was 53 and above, males being more affected than females, which can significantly affect some of the productive life of the individuals and thereby also affecting the working capacity .

Various recent reports have also appeared in literature, that between 2010 and 2015, India is projected to cumulatively lose USD 236.6 billion because of increased cases of heart diseases, shaving $1 \%$ off the GDP. This trend is having a marked impact on both the increased importance of insurance providers and TPAs in the future paving more way for the health insurance to reduce the out of pocket expenses which at present are more than $75 \%$.

An important finding of the present study was, education wise the average percentage of policy holders having graduation and above across all the 4 hospitals is $75 \%$, which clearly suggests that education levels do have a positive influence. Another important finding was on comparing the income level of the insured cardiac patients across the 4 hospitals of Indore, Bhopal and Delhi, the percentage of insured policy holders in all 


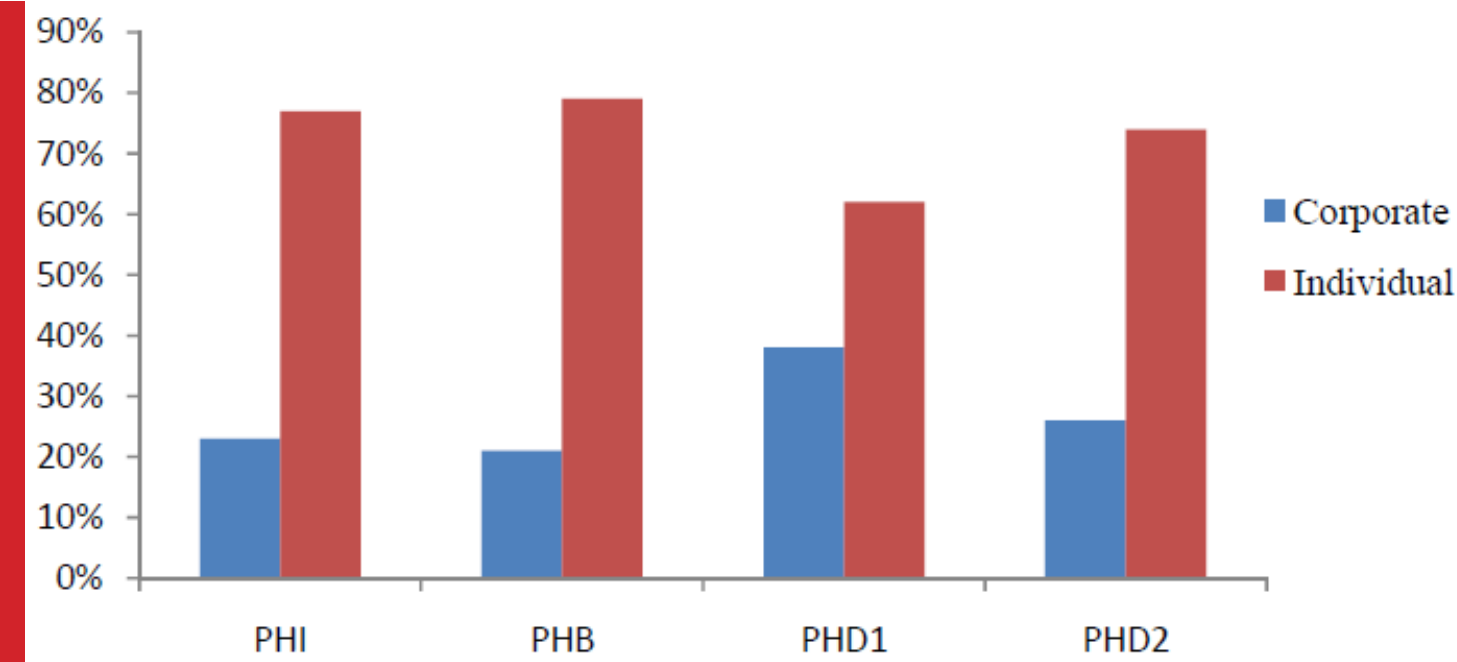

Policy holders (Corporate / individual ) of private hospitals

FIGURE 5: Showing the comparative data with regard to corporate versus individual policy holders in 4 Hospitals of MP and Delhi

the four private hospitals under study having monthly income of more than Rs. 20,000 was around $86 \%$ which clearly suggests that income levels do have a positive influence on the having health policy. The data also suggest that the category of people with low income who need health insurance policy the most do not have it. Secondly, around $50 \%$ of insured cardiac patients were found to be in the category of income of Rs. 20,000 - 50,000 suggesting that people earning from this category have the largest share in having health insurance cover in all the cities selected for the study.

\section{REFERENCES}

Balrajan Y, S Selvaraj, SV Subramanian (2012) Health care and equity in India, The Lancet, Volume 377, Issue 9764 Pp 505-515

Delloitte ASSOCHAM Report (2011) Cardiovascular Diseases in India Challenges and Way Ahead www.deloitte.com

Deloitte India (2015) Deloit India Healthcare Report India Outlook 2015

HIFA (2015) Health Care Information for all by 2015 :http:// www.hifa 2015.org

Industry Report, Health Care India, (2014)

Kumar AKS, LC Chen, M. Chaudhary, S. Ganju, V. Mahajan, A. Sinha, A. Sen (2012) Financing health care for all: Challenges and Opportunities, The Lancet, Volume 377, Issue 9766, Pp 668-679.

Paul VK, Sachdev HS, Mavalankar D (2012) Reproductive Health and child health and nutrition in India: meeting the challenge. The Lancet, Volume 377.

Shaima Miraj (2015) Can going to the grass roots help in meeting the challenges of universal health management and marketing in developing countries International Journal of Health Management Maney Online (UK)DOI abs/10.1179/2047971915Y

Shaima Miraj (2015a).Amelioration of our diseased health care system:Role of health insurance and the government as partners BBRC Vol 8 (1) 5-7

Shaima Miraj (2014),Better approaches for our ailing health care system. Current Science Vol 107- 4,558

Shaima Miraj (2015b)Some problems and solutions of public health scenario in developing countries Health Science Communication BBRC Vol 8 (2) 104-109

Suman, De and B. Mishra (2007) IIFMR \& IHMR, Report Community Based Health Financing in Jharkhand 2007

WHO (2008) The World Health Report 2008 Working Together for Health. Geneva: World Health Organization; 2008a.

Wilson, C. (2009) Dis-embedding Health Care: Marketisation and the Rising Cost of Medicine in Kerala, South India. Journal of South Asian Development 4: 83-101. 